\title{
PUEBLOS INDÍGENAS Y PRÁCTICAS DOCENTES EN LA ESCUELA SECUNDARIA. EL TRATAMIENTO DE LA FRONTERA DEL SUDOESTE BONAERENSE DEL SIGLO XIX
}

INDIGENOUS PEOPLEAND TEACHING PRAGTICES IN HIGH SCHOOL.

THE TOPIC OF SOUTHWESTERN OF BUENOS AIRES PROVINCE (ARGENIINA) FrONIIER IN THE XIXTH CENTURY

Hernán Perrière ${ }^{1}$ Articullo Recibido: 15 de diciembre 2019 / Articullo aceptado: 2 de abril 2020

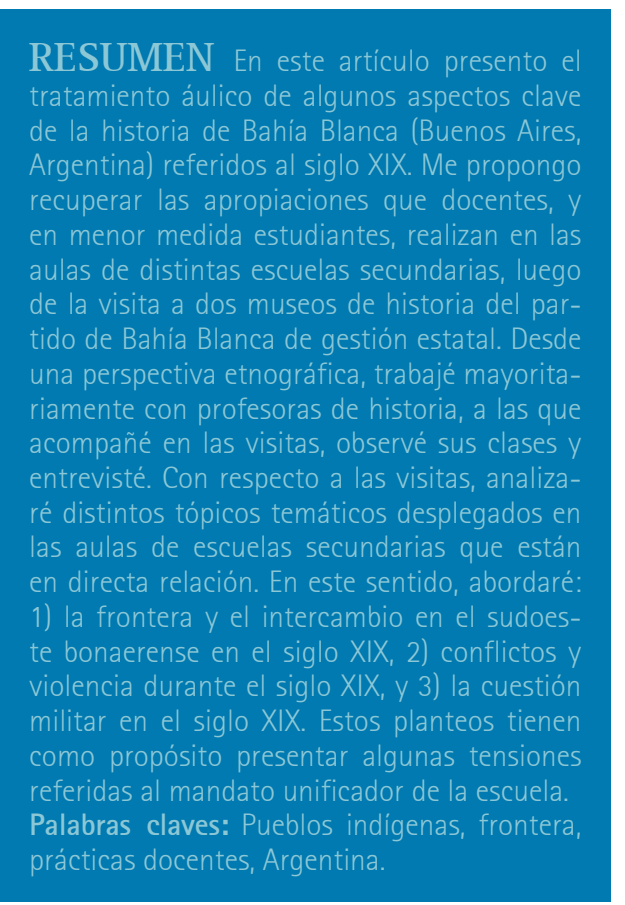

${ }^{1}$ Dr. en Antropología Social, Universidad de Buenos Aires (UBA). Profesor y licenciado en Historia, Universidad Nacional del Sur (UNS). Docente del Dpto. Humanidades (UNS).

Correo electrónico: hernanperriere@hotmail.com

${ }^{2}$ La ciudad de Bahía Blanca se encuentra a unos $680 \mathrm{~km}$ al sur de la Ciudad Autónoma de Buenos Aires, capital de la República Argentina. Fue fundada en 1828, y el proyecto de fundación se impulsó durante la presidencia de Bernardino Rivadavia, en 1827, frente al peligro de la ocupación militar brasilera de la localidad de Carmen de Patagones durante la guerra con el Brasil (1825-1828).

\section{INTRODUCCIÓN}

En este artículo propongo mirar a la escuela y la enseñanza de la historia local en la "escala cotidiana" (Rockwell, 2009: 78), ya que alli adquieren importancia los saberes, prácticas y concepciones de los sujetos que la transitan, cuya reconstrucción permite dar cuenta del papel de los sujetos en la reproducción social más amplia, en este caso, sobre los pueblos indígenas y la frontera en el siglo XIX. Me interesa analizar el tratamiento de algunos aspectos clave de la historia de Bahía Blanca y su abordaje en las aulas, en los cuales se produce una vinculación directa con las visitas a los museos que docentes y estudiantes realizan, aunque estas se abordaran tangencialmente ${ }^{2}$.

En este sentido, prefiero hablar de prácticas docentes, definida en su significación social y particular por la práctica pedagógica, pero que va mucho más allá de ella, al involucrar una compleja red de actividades y relaciones que la traspasa (Achilli, 1985, 1986). Si bien en este artículo la mirada está centrada en los procesos áulicos, incluye también decisiones y actividades que las docentes planifican, entre ellas, visitar museos.

Durante la investigación etnográfica (2014-2018) en escuelas y museos de gestión estatal, trabajé mayoritariamente con profesoras de Historia. Metodológicamente, la elección de las docentes, cuyas experiencias se presentan en este escrito, partió de los listados que los museos tenian sobre las visitas escolares. Es decir, el vínculo con las docentes se generó desde sus prácticas recurrentes de visitar museos. La elección de las escuelas donde observé el tratamiento áulico sobre los pueblos indígenas y la frontera estuvo determinada por la relación entre los museos y las escuelas. Las mismas son escuelas secundarias públicas dependientes de la Dirección General de Escuelas de la Provincia de Buenos Aires (DGEPBA) y pertenecen a distintos barrios de la cuidad, distantes entre sí. Por esto, el traslado de los cursos y las docentes hacia los museos se realizó por colectivo de línea o por medio del programa municipal ¿Conocés Bahía? que invita a las escuelas a conocer los museos y, por esto, brinda colectivos para los recorridos hacia ellos. 
De Prácticas y discursos

Universidad Nacional del Nordeste

Centro de Estudios Sociales

Año 9, Número 13, 2020, Marzo

ISSN 2250-6942

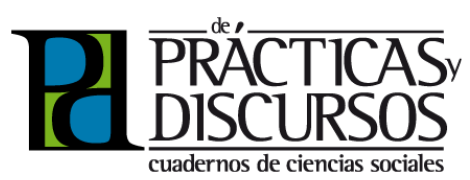

ABSTRACT In this article I present the

high school aulic treatment of key aspects of the XIXth century history of Bahía Blanca city (Buenos Aires, Argentina). I intend to recover the appropriations that teachers and, to a lesser extent, students do in the classrooms after visiting two history museums. From an ethnographic perspective, I mostly worked with history teachers, whom I accompanied on visits, observed their classes and interviewed. In relation to the visits to these museums, I will analyze and discuss different topics deployed in the classrooms, including: 1) the frontier and the exchange of goods, 2) the conflicts and violence and 3) the military issue. These proposals are intended to present some tensions related to the unifying mandate of the school.

Key Words: Indigenous people, frontier, teaching practice, Argentina.

\begin{abstract}
${ }^{3}$ Los nombres de las escuelas y de las docentes son ficticios para preservar su identidad. Estas escuelas tienen características distintivas. La escuela Federal y la Céntrica son escuelas a la que acuden mayoritariamente jóvenes de clase media, en la primera sobre todo del barrio, en la segunda, por su ubicación en el centro, confluyen, además, estudiantes de otros barrios. A la escuela Mitre asisten estudiantes de clase media baja y de sectores populares de los barrios cercanos.
\end{abstract}

${ }^{4}$ Siguiendo este esquema se organizan las unidades: Unidad 1: Crisis del orden colonial. Guerras de la independencia, Unidad 2: Cambios en la estructura política, económica y social latinoamericana en la primera mitad del siglo XIX, Unidad 3: Transformaciones en el capitalismo, imperialismo y colonialismo, y Unidad 4: La organización de la Argentina moderna. Historia de contrastes.
En este trabajo presento las prácticas áulicas de tres docentes que he llamado Florencia, Araceli y Sonia, que son profesoras de tercer año de distintas escuelas secundarias (Mitre, Céntrica y Federal), respectivamente 3 . Es en este año en el que las temáticas sobre la frontera forman parte de los contenidos curriculares en común con la materia Geografía: "la conformación espacial e histórica del Estado argentino justificada por su relevancia social y su pertinencia en la formación de estudiantes de esta etapa especifica de la escolaridad" (Diseño Curricular para tercer año [ES], 2008: 119). El marco histórico de los contenidos se extiende por lo tanto desde la crisis en el orden colonial a fines del siglo XVIII y principios deI XIX, hasta la formación y consolidación de los Estados nacionales a fines del siglo XIX y principios del XX4. Este tratamiento de lo local alude permanentemente a cuestiones y procesos nacionales, se da un "ida y vuelta" entre lo local y lo nacional. Incluye, además, temáticas históricas que permiten poner en relación procesos acontecidos en el siglo XIX en Bahía Blanca y en el país. Los tópicos que he elegido para analizar estas problemáticas en las aulas refieren a un periodo de particular importancia del pasado regional: un eje cronológico que se inicia con la fundación del Fuerte que da origen a la ciudad en 1828 (Fortaleza Protectora Argentina) y que culmina con la llegada del ferrocarril y la creación del puerto de Ingeniero White en 1884. Estos dos hitos fundacionales son disímiles en términos de los procesos históricos a los que aluden, ya que el primero refiere a una campaña militar de las tantas que se realizaron en el sudoeste bonaerense, mientras que el segundo remite a la instalación de una infraestructura comercial y de transporte integrada al sistema agroexportador.

Ambos hitos son considerados fundadores de la ciudad en las narrativas construidas desde las esferas oficiales y señalados como "la primera" y "la segunda" fundación de Bahía Blanca. Sin embargo, hay pocas referencias al periodo conflictivo de relaciones interétnicas que precedió y acompañó este proceso históri$\mathrm{co}$, el que resulta parte constitutiva de la historia local y nacional. Sostengo que la relevancia de estos "hitos fundadores" han invisibilizado un periodo conflictivo de relaciones interétnicas, fortaleciendo las consecuentes perspectivas de una ciudadanía desindigenizada (Lenton, 2010; Delrío, 2015; Nagy, 2012).

En las clases observadas y en las entrevistas realizadas a las docentes surgieron otros aspectos temáticos que se relacionan con 
De Prácticas y discursos

Universidad Nacional del Nordeste

Centro de Estudios Sociales

Año 9, Número 13, 2020, Marzo

ISSN 2250-6942
Pueblos indígenas y prácticas docentes en la escuela secundaria.

El tratamiento de la frontera del sudoeste bonaerense del siglo XIX

Indigenous people and teaching practices in high school. The topic of southwestern

of Buenos Aires province (Argentina) frontier in the xixth century

\begin{abstract}
${ }^{5}$ La llamada Campaña al Desierto no debe confundirse con la "Conquista al Desierto" impulsada por Julio Argentino Roca. La primera consistió en diferentes expediciones militares que impulsó Rosas con el apoyo de algunos gobernadores provinciales durante 1833 y 1834. Para indagar sobre la coyuntura del gobierno de Juan Manuel de Rosas, recomiendo la lectura de Jorge Gelman (2004).
\end{abstract}

${ }^{6}$ Florencia es profesora de Historia en distintas escuelas de Nivel Secundario y en un instituto de formación docente. Se recibió en la Universidad Nacional del Sur. En el momento de la investigación tenía aproximadamente 55 años. En una de las entrevistas que le realicé, me comentó que su interés por la historia comenzó cuando estaba cursando la escuela secundaria y participó en un certamen sobre historia de la ciudad en 1978, al cumplirse el $150^{\circ}$ aniversario. el periodo de estudio (1828-1884), los que me permitieron considerar cómo se abordan en las aulas las problemáticas relacionadas centralmente con los pueblos indigenas y específicamente a las vinculadas con la frontera. Con respecto a algunos aspectos que se abordaron en las visitas a los museos, analizaré ahora tres tópicos temáticos desplegados en las aulas: 1) la frontera y el intercambio en el sudoeste bonaerense durante el siglo XIX, 2) conflictos y violencia en la frontera durante el siglo XIX, y 3) la cuestión militar en el siglo XIX.

Es importante aclarar que la división en tópicos de análisis no significa su tratamiento diferencial por clases, sino que más bien corresponden a distintas temáticas referenciadas en una o varias clases. Para su contextualización se analizarán brevemente, además de las formas en que se presentan los contenidos en el aula, las estrategias didácticas utilizadas, los recursos pedagógicos y las actividades planteadas por las docentes a sus estudiantes.

\section{1.- LA FRONTERA Y EL INTERCAMBIO EN EL SUDOESTE BONAERENSE DURANTE EL SIGLO XIX}

El fuerte de Bahía Blanca fue fundado en 1828, y entre 1833 y 1834, el entonces gobernador de la provincia de Buenos Aires, Juan Manuel de Rosas, impulsó la denominada Campaña al Desierto ${ }^{5}$. En su traslado al Río Colorado, pasó personalmente por la fortaleza y mandó a construir el Ilamado "Zanjón de Rosas" en las cercanías del arroyo Maldonado. Por ese entonces, el sudoeste bonaerense formaba parte de un área marginal, lejos del centro de poder y rodeado por los pueblos indígenas de la Pampa y la Patagonia, por lo que era claramente una zona de frontera. Para Florencia ${ }^{6}$, una de las docentes que entrevisté y observé sus clases de tercer año en la escuela Mitre, el tema de las relaciones interétnicas desde una perspectiva histórica requería cierto refuerzo para su abordaje. Para facilitar que los estudiantes se familiarizaran con un tema poco transitado por ellos con anterioridad, planificó la visita al Museo y Archivo Histórico de Bahía Blanca (MAHBB) como una herramienta importante de apoyo de su trabajo en el aula.

En una de las clases previas a la visita al MAHBB, Florencia decide presentar a los estudiantes distintos flyers sobre actividades que había realizado el museo, con la finalidad de que describan la imagen y las actividades que se promocionan, asociadas a even- 
De Prácticas y discursos

Universidad Nacional del Nordeste

Centro de Estudios Sociales

Año 9, Número 13, 2020, Marzo

ISSN 2250-6942

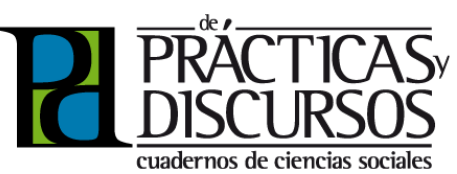

tos de la vida cotidiana. De esa forma, procuraba desplegar la idea de frontera dinámica, recuperando los conocimientos previos de los estudiantes. Esta propuesta de actividad requirió que la docente estableciera una relación previa con el MAHBB, así como un recorrido por la página web para seleccionar las invitaciones a las actividades. Uno de estos folletos se titulaba: "Sobrevivir a la frontera. Charla sobre la vida cotidiana en la época de la fundación de la ciudad". En relación con esta temática y en el transcurso de la clase, se presentó el siguiente diálogo entre Florencia y un alumno:

F (Florencia): ¿Qué duda tienen? Antes no había ciudades ¿Dónde vivían antes de las ciudades?

A (alumno): Indios...

F: ¡Claro! Entonces habia una frontera, una frontera de contacto... (con el tono indica que espera una respuesta por parte de los estudiantes).

A: ¡Ah! Entre los civilizados y los pueblos indígenas...

F: Eh... (duda). Bueno, podés ponerlo así... el asunto es que si vos hablás de civilización...

A: (interrumpe). Entre la civilización y los que pagaron la tierra a los indígenas (ensayando una interpretación del conflicto).

F: (retoma) ¿Vos estarías de acuerdo en que la ciudad era lo civilizado y los indios eran salvajes?

A: ¡No! 0 sea... ellos también podian tener su civilización.

F: ¡Ah! ¡Ellos también tenían su civilización. Entonces... eso que vos decís...

A: (interrumpe). La civilización tenía mucha gente.

F: ¡Perfecto! ¡Tenés razón! Yo estoy de acuerdo con vos (...) Es importante que puedas pensar que eso de civilizado era un discurso de aquel momento, pero no el tuyo ahora. Vos no lo pensás igual... Pero en aquel momento se pensaba que la civilización era lo blanco, lo urbano. Entonces se empezaba a ver a los indios como salvajes (...) Tenés razón, iasí se pensaba en aquel entonces! (Registro de clase, escuela Mitre, 5 de septiembre de 2016).

En este diálogo resulta significativa la emergencia de la complejidad señalada por Florencia para pensar las relaciones de frontera: ella las adjetiva como "de contacto", aunque el flyer habla de "sobrevivencia". Esta misma idea de conflicto surge cuando el estudiante se refiere inicialmente a la presencia indigena a partir de la dicotomía civilización-barbarie, que la docente trata de matizar. Es interesante que el alumno plantee el conflicto buscando una 
De Prácticas y discursos

Universidad Nacional del Nordeste

Centro de Estudios Sociales

Año 9, Número 13, 2020, Marzo

ISSN 2250-6942
Pueblos indígenas y prácticas docentes en la escuela secundaria.

El tratamiento de la frontera del sudoeste bonaerense del siglo XIX

Indigenous people and teaching practices in high school. The topic of southwestern of Buenos Aires province (Argentina] frontier in the xixth century

clave de interpretación espacial basada en dos polos: el campo y la ciudad, entre "la civilización y los que pagaron la tierra a los indígenas". Si bien "lo civilizado" y "los compradores" hacen referencia a la población blanca (donde el estudiante trata de ubicar un potencial conflicto de intereses), lo indígena aparece asociado a la tierra y lo rural, como algo distinto de lo civilizado.

Inicialmente, el alumno asoció la frontera a su sentido convencional en la historia liberal nacionalista, como un espacio de conflicto entre la "civilización" y los "pueblos indigenas", interpretación frente a la cual la docente añade la categoria "salvajes" para tensionar estas nociones. Esto hace que, cuando la docente relativiza las categorias que el alumno había utilizado ("civilización-barbarie"), este responda que los indígenas "también tenian su civilización", lo que le permite a Florencia reponer que el sentido de esta categoría es resultado de una construcción histórica. Al establecer esta expansión de la categoría de "civilización", la interpretación a la que llega el alumno es más amplia que la que brinda el flyer. En el folleto se presenta un dibujo del fuerte de Bahía Blanca y se representa una aldea con casas de techos a dos aguas de paja, una torre que simula la entrada al fuerte y carretas tiradas por caballos manejados por una persona y otras que están montando. La lectura de esa imagen puede suscitar múltiples interpretaciones, pero al estar encabezada por el título "sobrevivir en la frontera", da una idea de provisionalidad y riesgo que no se menciona, sino indirectamente por una fortificación que preanuncia un conflicto armado.

Esta idea de "frontera híbrida y mestiza hecha de tensiones y acuerdos, intercambios entre criollos e indios" está presente en el guion de MAHBB desde una reconstrucción de las formas de vida indigenas ahistorizadas $y$, sobre todo, desde el conflicto bélico. Sin embargo, es importante notar que los estudiantes de Florencia llegaron al museo con la idea, diferencialmente apropiada por cada uno de ellos, de que hubo conflictos en la frontera, no solamente porque se habian producido ataques indígenas a poblados pobremente defendidos por fortines, sino por una violencia ejercida por quienes definían unilateralmente que encarnaban la "civilización".

Como mencioné más arriba, en las narrativas oficiales sobre la historia argentina, la dicotomía "civilización y barbarie" constituyó un fuerte patrón ideológico y discursivo de la organización de la otredad. El mito del "desierto" se basa, al decir de Briones (2008), 
De Prácticas y discursos

Universidad Nacional del Nordeste

Centro de Estudios Sociales

Año 9, Número 13, 2020, Marzo

ISSN 2250-6942

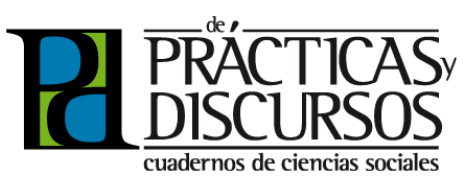

en la idea de una frontera tierra adentro bajo el control de las parcialidades indigenas "salvajes", diferenciada de la sociedad "civilizada" como si se constituyera como un límite infranqueable. Esta idea es cuestionada en las clases de Florencia previas a la visita al $M A H B B$, inicialmente desde un interrogante que propone la docente, pero que es asimilada por el estudiante con el que dialoga en el fragmento anterior, mostrando la construcción de una idea matizada y más compleja de frontera. Esta idea no solo cuestiona la justificación de la violencia y genocidio indígena, sino que abre la posibilidad de vislumbrar distintos tipos de intercambios económicos y sociales entre indígenas y criollos.

Destacando esa idea de "interacción" en el trabajo en el aula con posterioridad a la visita al museo, Florencia hará referencia al intercambio de productos para la vida cotidiana, apoyándose en los objetos exhibidos en el MAHBB y enfatizando el intercambio de productos, pertenencias o "vituallas":

Florencia (F): Muy bien, los chicos (dirigiéndose a los alumnos) utilizaron una palabra nueva... Y decíamos que en esa frontera había toda un área de contacto en que la población blanca intercambiaba con la población aborigen lo que se usaba para vivir, fuera alcohol, fuera armas, fuera caballos, ¿si? Entonces ese conjunto de cosas para la vida cotidiana se la Ilama vituallas (Registro de clase, escuela Mitre, Bahía Blanca, 12 de septiembre de 2016).

Entrevistada con posterioridad a la visita al museo, Florencia destacó que los estudiantes reconocian que el actual territorio de la provincia de Buenos Aires había estado ocupado por pueblos indígenas en el momento de la fundación de Bahía Blanca, pero que antes de ir a visitar el MAHBB, en sus clases habia notado que, para ellos, no había relación entre las dos sociedades y, por lo tanto, la frontera era un límite estático. Así lo relata:

Florencia (F): ¡Mira vos! (pensé). Ellos (los alumnos) saben que ese territorio estaba ocupado por aborígenes, pero no podían pensar esa área como una zona de interacción. La frontera como un espacio de interacción. Para ellos no tenía nada que ver. Los indios por un lado y después llegaron los blancos... y ahi me parece que tenemos también un tema pendiente.

Hernán $(\mathrm{H})$ : ¿Cómo planteaste ese problema?

F: Esta cuestión de... la relación entre la poca población blanca y la población de los fortines con las comunidades indígenas... ¿no? 
De Prácticas y discursos

Universidad Nacional del Nordeste

Centro de Estudios Sociales

Año 9, Número 13, 2020, Marzo

ISSN 2250-6942
Pueblos indígenas y prácticas docentes en la escuela secundaria.

El tratamiento de la frontera del sudoeste bonaerense del siglo XIX

Indigenous people and teaching practices in high school. The topic of southwestern

of Buenos Aires province [Argentina] frontier in the xixth century

\begin{abstract}
${ }^{7}$ Esta idea de frontera dinámica abordada por la docente se sostiene desde el campo disciplinar de la historia por Mandrini (1992, 2008), quien fue uno de los primeros en describir el concepto de relaciones interétnicas a partir de plantear una frontera dinámica frente a la idea de límite o delimitación característica de los estudios anteriores. Mandrini propuso que no había una separación rígida entre las tierras de los indígenas y la de los criollos, ya que cada una de estas sociedades intervino en un espacio común, produciendo relaciones comerciales fluidas sin perder las formas de vida particulares (Villar, 2012; Villar y Jiménez, 2004).
\end{abstract}

Para ellos eran dos mundos, y dos sociedades totalmente separadas, y conocer de la interacción les llamó mucho la atención (...) $\mathrm{H}$ : ¿Y cómo abordaste el tema de la interacción después en el aula?

F: Y... por ejemplo, con los productos, porque se necesitaban o porque tenían contacto para la vida cotidiana... (Entrevista a Florencia, Bahía Blanca, 18 de mayo de 2016. El resaltado es del autor).

Como puede observarse en su testimonio, la docente se propuso utilizar la visita al MAHBB para incorporar una visión de frontera dinámica en su trabajo en el aula, donde las interrelaciones entre criollos e indígenas estaban presentes durante los primeros tiempos de establecimiento del Fortaleza Protectora Argentina (fuerte de Bahía Blanca) ${ }^{7}$.

Esta idea de "interacción" o de frontera dinámica es, a su juicio, un "tema pendiente" en el tratamiento historiográfico, de ahi la utilización del "nosotros" que implícitamente me incluia, ya que ambos somos investigadores. Si bien no se detiene en esto, la evidencia de esta conceptualización historiográfica estaría dada por los conocimientos previos de los estudiantes, que en su experiencia habian asimilado la idea evolutiva que los indios fueron sucedidos por los blancos (Los indios por un lado y después llegaron los blancos...) estableciendo fronteras no solamente espaciales (el campo y la ciudad), sino también temporales (antes y después) consensadas ambas en la dicotomía entre "barbarie y civilización".

Por otra parte, en la entrevista, Florencia me explicó que en sus clases trabajó acerca de la decisión de B. Rivadavia de extender la frontera agrícola, así como de la política de J.M. de Rosas para mantener la fortaleza estableciendo acuerdos con los indigenas. Esto ponía en juego no solo las relaciones entre pueblos indígenas y criollos, sino también la significación de la frontera como un espacio dinámico en el desarrollo de las políticas estatales y de los grupos dominantes para construir un Estado unificado. Es importante mencionar que en el contexto en que Florencia ubica su narración, Bahía Blanca se había convertido en un punto central de los contactos interétnicos en el sur bonaerense, con el cacique Calfucurá instalado en Salinas Grandes desde 1840 como "indio amigo", convirtiéndose así en uno de los principales destinatarios de raciones y obsequios del gobierno rosista. Según Ratto (2004), en 1830 el fuerte de Bahía Blanca solo contaba con cuatro pulperos, pero la cantidad de negocios 
De Prácticas y discursos

Universidad Nacional del Nordeste

Centro de Estudios Sociales

Año 9, Número 13, 2020, Marzo

ISSN 2250-6942

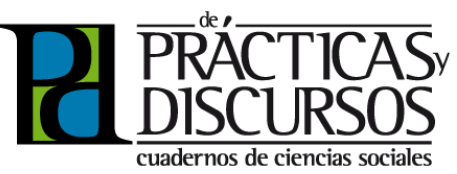

aumentó hasta llegar a contar en 1838 con quince negocios. En la década de 1840 se produjo otro crecimiento de la ciudad, cuando algunos vecinos de Patagones y otras fortificaciones se trasladaron a Bahía Blanca, entre ellos, el conocido lenguaraz Francisco Iturra, quien estableció el monopolio en la compra de cueros a los indios de distintos grupos.

En este sentido, es interesante señalar que, en una de las clases posteriores a la visita, Florencia recuperó la visita al MAHBB presentando a los estudiantes distintos extractos de textos sobre la frontera bonaerense, para que los estudiantes complementen con más información los objetos observados en el museo. En la entrevista me comentó que su objetivo con estos textos fue mostrar el dinamismo de las relaciones sociales en la frontera a partir de una compleja red de sujetos sociales, de creencias religiosas, de procesos de etnicidad y mestizaje característicos de la frontera pampeana, tal como surge del siguiente extracto del texto entregado en la clase:

Uno de los rasgos comunes señalados para los habitantes de la campaña (criollos, indígenas e incluso inmigrantes) era el intercambio de vestimenta... Las pulperías fueron escenarios fundamentales en el medio rural, alli se organizaban diferentes actividades y sirvieron como uno de los espacios de sociabilidad más relevantes. [Ratto, 2013]. (Registro de clase, escuela Mitre, 5 de septiembre de 2016).

La docente presentó estos textos como información complementaria a la visita y no se detuvo a analizarlos en profundidad en la clase, sino que más bien se dedicó a recuperar la experiencia en el MAHBB a partir de relatos y dibujos sobre los objetos en exhibición. Si bien esta actividad parece no sacar provecho del recurso, es necesario contextualizar la propuesta de Florencia respecto de la problematización de la frontera como zona de contacto dinámica dentro de los contenidos del Diseño Curricular de la Provincia de Buenos Aires (DCPBA) para tercer año de la escuela secundaria, para asi entender el desafío que ella se plantea.

En el DCPBA para tercer año se propone comprender la "inserción de la Argentina en el modo de producción capitalista", pero es evidente la ausencia de temas necesarios para analizarla, especialmente la llamada Conquista al Desierto, a la que no se menciona. En los contenidos a enseñar no aparece en toda la unidad la palabra indio, indígena, comunidad o pueblo origina- 
De Prácticas y discursos

Universidad Nacional del Nordeste

Centro de Estudios Sociales

Año 9, Número 13, 2020, Marzo

ISSN 2250-6942
Pueblos indígenas y prácticas docentes en la escuela secundaria.

El tratamiento de la frontera del sudoeste bonaerense del siglo XIX

Indigenous people and teaching practices in high school. The topic of southwestern of Buenos Aires province [Argentina] frontier in the xixth century

rio. Solo se hace mención a la "situación social en la frontera y a la integración del territorio" (Perrière, 2014: 383).

En este documento se enuncia la importancia de analizar la construcción de identidades subalternas, así como la consideración de los procesos históricos en una trama multicultural. Sin embargo, la mención elusiva a los pueblos indígenas contrasta con otros actores como campesinos, colonos, asalariados, inmigrantes, terratenientes, peones, jornaleros, burgueses, chacareros, elites oligárquicas y viajeros, que aparecen en innumerables contenidos. Las únicas menciones en los contenidos a enseñar referidas a los indígenas en el DCPBA son su participación en la Revolución mexicana, bajo el colectivo de campesinos, y los conflictos políticos entre 1820-1852 en el Río de la Plata, bajo el término "caciquismo". Como analicé en un trabajo anterior (Perrière, 2014), esta mirada puesta en el caciquismo y el caudillismo como expresiones de un mundo rural, responsables en parte de los conflictos políticos tendientes a desestabilizar a los primeros gobiernos nacionales, es una imagen que proporciona poco margen para problematizar las relaciones sociales en un Estado en construcción.

Las referencias menores sobre los pueblos indigenas en las materias de Historia en la escuela secundaria no solo están invisibilizadas en los diseños curriculares actuales. El historiador Mariano Nagy (2013) analizó que los lineamientos curriculares que se establecieron de acuerdo a la Ley provincial de Educación № 11612 sancionada en Buenos Aires en 1994, acorde a lo planteado por la Ley Federal de Educación, no incluyeron referencias a los pueblos indígenas en los contenidos de la asignatura Historia para el tercer ciclo de la antigua Educación General Básica $\left(1^{\circ}, 2^{\circ}\right.$ y $3^{\circ}$ año), como tampoco en el Polimodal $\left(1^{\circ}, 2^{\circ}\right.$ y $3^{\circ}$ año), que conformaban la vieja estructura del Nivel Secundario hasta 2006. En la asignatura Historia Argentina y Latinoamericana del siglo XIX, que se dictaba en el primer año del Polimodal, no se mencionaba a los pueblos indigenas y solamente hay una escueta mención a la "problemática indígena" en la materia Historia Argentina y Latinoamericana del siglo $X X$, sin ningún tipo de aclaración a qué tipo de problemática se refiere en un periodo que abarca de 1930 a 1970.

Como señalé anteriormente, Florencia realizó un tratamiento particular sobre la frontera, otorgando a las relaciones interétnicas un lugar protagónico en sus clases. Puedo suponer que 
De Prácticas y discursos

Universidad Nacional del Nordeste

Centro de Estudios Sociales

Año 9, Número 13, 2020, Marzo

ISSN 2250-6942

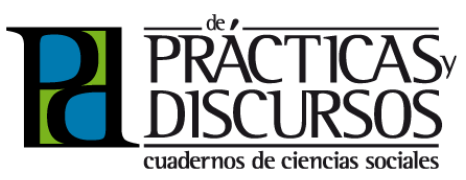

dicho tratamiento tiene que ver con su trabajo como profesora de Historia Argentina del siglo XIX en un instituto de formación docente en la carrera de Historia, lo que le pudo haber proporcionado un espacio de reflexión adicional sobre el tema. También por su interés en capacitarse en estas temáticas, ya que, en un intercambio informal, ella me comentó que planeaba cursar un seminario de posgrado con Ratto en el Departamento de Humanidades de la UNS sobre relaciones interétnicas.

\section{2.- CONFLICTOS EN LA FRONTERA DURANTE EL SIGLO XIX: ZANJAS, FORTINES Y MALONES}

La presentación de la frontera bonaerense como una zona de conflicto y violencia durante el siglo XIX fue recurrente en las clases observadas. Anteriormente, analicé lo sucedido en la clase de Florencia y a modo introductorio, a continuación, profundizaré el tema a partir de una de las clases de Sonia ${ }^{8}$ en la escuela Federal, que pondré en relación con las clases de la primera docente presentada.

Cuando me acerco a su aula, para observar la preparación de la visita, encuentro que Sonia inicia con una clase expositiva y dialogada con la presentación de un power point, preguntando a sus alumnos sobre la historia de Bahía Blanca y de General Daniel Cerri como preparación de la visita al Museo Fortín Cuatreros (MFC). La docente comienza presentando la "parte histórica" del sudoeste bonaerense, con las primeras expediciones ultramarinas de reconocimiento de la región, mostrando dos mapas históricos. Su intención fue introducir a los estudiantes en la historia de la localidad de General Daniel Cerri, donde se encuentra el museo que visitará. Para la docente y para la comunidad de Cerri, el fortín Cuatreros fundado por encargo de A. Alsina, al margen del río Sauce Chico, representa el nacimiento del pueblo:

La docente está relatando cómo continúa el avance de la frontera luego del establecimiento del fortín, menciona pueblos originarios como los tehuelches de la región, pero también a otros como los wichis y dice:

Asi se fue corriendo la frontera entre los blancos y los aborigenes. Esto generó un vasallaje de la población indígena (...) El (río) Sauce Chico es como una zanja donde el indio no podia pasar... Pero también había otras zanjas como la de Alsina (...) 
De Prácticas y discursos

Universidad Nacional del Nordeste

Centro de Estudios Sociales

Año 9, Número 13, 2020, Marzo

ISSN 2250-6942
Pueblos indígenas y prácticas docentes en la escuela secundaria.

El tratamiento de la frontera del sudoeste bonaerense del siglo XIX

Indigenous people and teaching practices in high school. The topic of southwestern of Buenos Aires province [Argentina] frontier in the xixth century

La docente muestra un mapa con los partidos actuales que conforman el sudoeste bonaerense y marca la línea de fortines y la zanja de Alsina. Luego pregunta:

Sonia: ¿A qué les suena Cuatreros?

Alumna: ¡A chorizos!

La profesora aclara que el término tiene que ver con el robo de ganado (Registro de clase, escuela Federal, 21 de agosto de 2014).

A partir de este intercambio se puede notar que la docente hace alusión directa a la presencia de los pueblos indígenas en el territorio que fue denominado "desierto" por las campañas militares del momento mencionándolos directamente. Incluso, refiriendo a una parcialidad que no ocupaba el sudoeste bonaerense como el pueblo wichi, lo que podría pensarse como parte de un esquema conceptual subyacente, es decir, no explicitado en ese momento a los estudiantes, donde lo acontecido en Bahia Blanca es contextualizado en un marco mayor (de ahí tal vez la elección de un colectivo del Gran Chaco, en alusión a la campaña al "desierto verde"). Al mismo tiempo y con pocas palabras, Sonia "toma partido" al decir que los indígenas fueron avasallados, aunque no despliega cómo entiende ella este proceso de subordinación e incorporación violenta a la Nación. En el diálogo se presentan elementos que permiten intuir conflictos en la frontera bonaerense durante el siglo XIX: Ios avances indigenas, los fortines y zanjas militares.

La "Zanja de Alsina" refiere a la construcción de un largo foso que unió diferentes fortines del sur de la actual provincia de Buenos Aires, y su evocación se vincula con que fue el general Cerri el que levantó en 1876 los fortines Cuatreros, Palao y Borges que la vigilaban. La fortificación de la frontera estaba orientada a detener las incursiones de los indigenas para arriar ganado y ocupar las tierras de pastoreo donde alimentaban los ganados los caciques de Salinas Grandes: en particular dos meses antes de la fundación de Fortín Cuatreros, Cerri mencionó una sublevación de la tribu de Linares y Ralinqueo (Alsina, 1977).

Si bien estos temas no se profundizaron en el aula, Sonia presentó la línea de fortines para ubicar alli la creación del Fortín Cuatreros, explicitando que fue parte de la línea de frontera creada por Adolfo Alsina como ministro de Guerra en la década de 1870, previa a la campaña del general Roca, reconociendo así una de 
De Prácticas y discursos

Universidad Nacional del Nordeste

Centro de Estudios Sociales

Año 9, Número 13, 2020, Marzo

ISSN 2250-6942

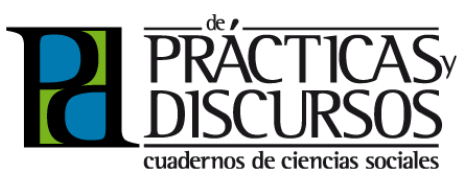

las estrategias que utilizó el Estado nacional para dominar a los pueblos indígenas y extender las fronteras mediante construcciones defensivas que delimitaron el paisaje en ese momento (Bayón y Pupio, 2003; Perrière, 2001, 2003, 2004, 2007)․ El fortín que da nombre al museo fue construido por instrucciones de Alsina, y fue el general Daniel Cerri el que se encargó de ejecutar dichas instrucciones en la margen izquierda del río Sauce Chico. Aunque la construcción original del fortín aún no fue localizada arqueológicamente, para los pobladores y los historiadores amateurs, el edificio que hoy ocupa el museo es el fortín original que dio origen al pueblo que lleva su nombre.

Como he mencionado, en otra de las clases observadas, Florencia (escuela Mitre) analizaba el flyer de una actividad que había desarrollado el MAHBB en la preparación de la visita con sus alumnos y en el momento de la puesta en común se produce el siguiente intercambio:

Florencia (F): Primera imagen (lee). Sobrevivir en la frontera. Alumno (A): La frontera... es una charla sobre la vida cotidiana en la época de la fundación...

F: ¡Muy bien! Es una charla sobre la vida cotidiana, lo que aparece del pasado (...) Bien, ¿era peligroso vivir en la frontera?

Varios alumnos responden: ¡Sí!

F: ¡Bien!... Entonces hay una experiencia de riesgo en la propia vida... ¿Esa experiencia de riesgo era solamente para el blanco?

A: No, ipara todos!

A: Se cruza un blanquito y también le daban (risas).

F: ¡Bueno! [La docente anota en el pizarrón: Experiencia de riesgo para la propia vida] (Registro de clase, escuela Mitre, 5 de septiembre de 2016)

En este fragmento, la docente asocia la frontera a la idea "sobrevivir", a la idea de "peligro" y "riesgo para la vida", colocando el conflicto vinculado a la violencia entre "los blancos" y "los indígenas" como un riesgo que no era "solamente para el blanco". Florencia, sin desarrollar el tema, sintetiza en forma genérica la idea escribiendo en el pizarrón: "experiencia de riesgo para la propia vida", donde el impersonal incluye a todos. De manera similar a lo que plantea Sonia, al mencionar que "se fue corriendo la frontera entre los blancos y los aborígenes", o que se generó una situación de "vasallaje", en este intercambio Florencia alude a la situación de la frontera como un espacio conflictivo y violento. 
De Prácticas y discursos

Universidad Nacional del Nordeste

Centro de Estudios Sociales

Año 9, Número 13, 2020, Marzo

ISSN 2250-6942
Pueblos indígenas y prácticas docentes en la escuela secundaria.

El tratamiento de la frontera del sudoeste bonaerense del siglo XIX

Indigenous people and teaching practices in high school. The topic of southwestern of Buenos Aires province [Argentina] frontier in the xixth century

\begin{abstract}
${ }^{10}$ La Legión Agrícola Militar o Colonia Agrícola Militar fue un proyecto económico y militar impulsado por el gobierno provincial en 1856, con la finalidad de realizar tareas agrícolas y la defensa de la frontera. Se establecieron en la margen izquierda del Sauce Chico y se extendió por solo dos años.
\end{abstract}

${ }^{11}$ Araceli es profesora de Historia, recibida en la UNS, docente de distintas escuelas secundarias y en algunas escuelas superiores de Arte. Tiene aproximadamente cerca de 50 años y es militante del Sindicato Unificado de Trabajadores de la Educación de la Provincia de Buenos Aires (Suteba).

\section{3.- CUESTIÓN MILITAR EN EL SIGLO XIX: CAMPAÑAS AL "DESIERTO"}

La presencia militar en la región de Bahía Blanca constituye un elemento central para entender parte de su historia. Como he mencionado, la ciudad se constituyó a partir de una campaña militar que fundó la Fortaleza Protectora Argentina. Durante el siglo XIX se impulsan otras campañas militares como la de Rosas (1833-1834), se establece la Legión Agrícola Militar (1859) ${ }^{10}$ y, por último, la línea de fortines creada por Alsina (1876).

Un tópico insoslayable en las clases es el de las campañas al "desierto", que forman parte del tratamiento de la cuestión militar desde la historia escolar. Al respecto, la docente Araceli11 menciona al referirse al proyecto de salida educativa al MAHBB que realizó con tercer año de la escuela Céntrica:

El tratamiento de la fundación de Bahía Blanca en 1828 incorpora nuevos temas y el tratamiento de las relaciones interétnicas durante las primeras "Campañas al Desierto", donde no hay una coyuntura diferente para el tratamiento de la frontera en las campañas de Alsina y Roca. En las primeras décadas del siglo XIX las relaciones interétnicas fueron dinámicas: distintos contingentes de indios amigos residieron en Bahía Blanca y fueron incorporados a funciones militares. (Entrevista a Araceli, Bahía Blanca, 7 de abril de 2016)

En esta descripción que realiza Araceli, respecto de su enfoque, hay un punto central para analizar el tratamiento de las campañas militares al territorio bonaerense, ya que ella asimila las "primeras campañas" de comienzos del siglo XIX, con las que luego emprendieron Alsina y Roca durante las décadas de 1870 y 1880. El historiador Enrique Mases (2010) ubica en 1815 las primeras preocupaciones de los gobiernos nacionales por el control de las fronteras bonaerense por medio de intervenciones militares. Las primeras expediciones son realizadas por Pedro A. García en 1810 y 1823, por el gobernador de Buenos Aires Martín Rodríguez en 1820, 1823 y 1824, y por el coronel Federico Rauch en 1826 y 1827. La afirmación de la docente refiere a que ella está queriendo transmitir a sus estudiantes que la frontera bonaerense no solo fue un área sin control del Estado, sino que también hubo constantes intervenciones militares durante todo el siglo XIX para 
De Prácticas y discursos

Universidad Nacional del Nordeste

Centro de Estudios Sociales

Año 9, Número 13, 2020, Marzo

ISSN 2250-6942

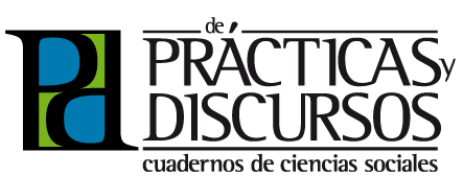

dominarla, sometiendo así a los pueblos indígenas. En ese mismo testimonio, Araceli también hace mención a los "contingentes de indios amigos que residieron en Bahia Blanca", que fue una de las principales estrategias de política rosista, acompañando el control de las fronteras hasta Bahía Blanca y Carmen de Patagones (Ratto, 2004; Villar, 2012).

Luego de la caída de Rosas, se inicia un periodo donde las parcialidades indígenas, sobre todo las de Calfucurá, iniciarán una ofensiva sobre la campaña y poblaciones fronterizas, como ya he mencionado. El problema de la frontera volvió a adquirir protagonismo público con el gobierno del presidente Nicolás Avellaneda (1874-1880). Para Mases (2010), las razones de tipo económico, las relacionadas con la soberanía y las imágenes del indio y el desierto hicieron de la cuestión indígena un tema central de aquí en más.

La política de Adolfo Alsina, ministro de Guerra y Marina, significó un cambio importante en el tratamiento de las parcialidades indigenas. Su estrategia para dominar el "desierto" fue la ocupación progresiva y la incorporación gradual de los indígenas a la sociedad blanca por medio de la interacción. Alsina muere en diciembre de 1877, obteniendo importantes logros para el Estado nacional: se incorporaron $56000 \mathrm{~km}$ de tierras apartas para la producción, los generales García y Vintter vencieron a Catriel y el coronel Villegas, a la tribu de Pichen entre octubre y noviembre de 1877. El general Julio Argentino Roca, que lo sustituyó como ministro, cambió la estrategia de Alsina por otra más ofensiva: avanzar hacia el Río Negro y Neuquén para atacar a las parcialidades indígenas en su centro de poder.

Esta breve descripción tiene la finalidad de mostrar una presencia permanente de campañas militares en el territorio bonaerense durante 60 años. El antropólogo Hugo Trinchero (2007) presenta una coyuntura más amplia para entender estos procesos, incorporando el "despliegue" corporativo del ejército mediante su profesionalización, efectivizada con la creación del Colegio Militar en 1869 y la Escuela Naval en 1872. También subraya la importancia de los relevamientos topográficos y el mapeo del espacio, mediante la creación de la Oficina Topográfica Militar (1884) y el Instituto Geográfico Militar en 1904, junto al crecimiento destinado a la seguridad por parte del Estado.

Además de estas estructuras institucionalizadas por el Estado, Trinchero (2007) asimismo analiza las expectativas del incremento patrimonial de sus integrantes por medio de la apropiación 
De Prácticas y discursos

Universidad Nacional del Nordeste

Centro de Estudios Sociales

Año 9, Número 13, 2020, Marzo

ISSN 2250-6942
Pueblos indígenas y prâcticas docentes en la escuela secundaria.

El tratamiento de la frontera del sudoeste bonaerense del siglo XIX

Indigenous people and teaching practices in high school. The topic of southwestern of Buenos Aires province (Argentina] frontier in the xixth century

territorial como botín de guerra, que fue una constante durante todas las campañas militares. Este modelo de enriquecimiento de los miembros del ejército basado en la "recuperación" de nuevas tierras fue una variable económica legitimada por los gobiernos provinciales y locales. En el análisis pude reconstruir que dos de las docentes prestaban atención a este proceso, llamándolo, entre otros términos, "avasallaje" de la población indígena.

En la propuesta de Araceli, así como en el resto de las docentes con las que trabajé, se hace referencia a las campañas militares durante el siglo XIX, pero no profundizan en la idea de que el ejército (o lo militar en general) funcionó en la campaña bonaerense como agente activo en la construcción del Estado nacional durante un siglo completo, atendiendo a sus matices. El rol del ejército en la constitución de las fronteras es generalmente presentado de manera emblemática con la campaña de J.A. Roca, probablemente por haber sido la más brutal y genocida.

Esto puede verse en una clase de la escuela Federal, previa a la visita al MFC, donde Sonia como docente de Geografía les mostró a sus alumnos un power point sobre la ocupación territorial y la historia de Cerri, explicando las primeras expediciones de reconocimiento de la ría de Bahía Blanca a partir de un par de mapas; luego la docente pasa a referirse al avance de la frontera y hace alusión a la Legión Agrícola Militar (1856-1858), pero no desarrolla en qué consistió ni su función como enclave militar y agrícola en el sudoeste bonaerense, ni tampoco cómo esta avanzada continuó en el tiempo.

En el caso de Florencia, las Campañas al Desierto adoptan una configuración aún más fragmentada. Luego de la visita al MAHBB, la docente intenta recuperar, en su clase de tercer año en la escuela Mitre, la visita realizada proponiendo a los estudiantes proyectar las fotos que habian tomado con sus celulares, cuestión que por problemas técnicos no pudo realizar. Ante esta dificultad, decide modificar su estrategia didáctica y plantea una actividad para que los estudiantes dibujen o relaten algo breve sobre la visita al museo:

Entra la preceptora a tomar lista, algunos estudiantes se paran, otros corren los bancos y se paran. Ante esto, la profesora dice: ¡Se acomodan de nuevo! ¡No hay imágenes! ¡Vamos a recuperar algo de la visita! y copia en el pizarrón: "El museo y el pasado, presente". Elegí una imagen, hacé un dibujo, escribi un relato breve sobre la visita al museo" (Registro de clase, escuela Mitre, 19 de septiembre de 2016, el resaltado es del autor). 
De Prácticas y discursos

Universidad Nacional del Nordeste

Centro de Estudios Sociales

Año 9, Número 13, 2020, Marzo

ISSN 2250-6942

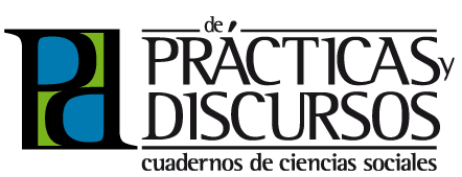

A lo largo de la clase se fue planteando un problema de comprensión en torno al título de la actividad: varios estudiantes me preguntaron a mi y a la docente qué debian hacer porque no entendian la relación del "pasado, presente", por ejemplo, preguntaron: "¿Hay que dibujar sobre un objeto del pasado y otro del presente? ¡Los objetos del museo son viejos, del pasado!", afirmó una alumna. La docente se acercaba a los bancos de los estudiantes y explicaba que la consigna era más general: que tenían que hacer un dibujo o relatar algo sobre la visita; en ese sentido, la visita debía remitir al presente, que es cuando se actualizaba el pasado patrimonializado.

Esta consigna de trabajo, que apelaba de manera general a la experiencia de los estudiantes en el museo, dejaba en un lugar ambiguo los contenidos que Florencia había trabajado previamente sobre el periodo fundacional de la ciudad (1828), sus momentos posteriores. Tampoco recuperaba de manera específica la visita al MAHBB, planteada según había explicitado, con el objetivo de trabajar con ese periodo histórico (razón por la cual el guía del museo solo se detuvo a explicar detenidamente el panel de la fundación, entre 1820-1884).

Ante una actividad presentada de manera amplia, los estudiantes mayoritariamente apelaron a su asociación libre con creatividad: una alumna dibujó un huevo roto con un simpático dinosaurio asomando con la leyenda: "fui al museo para aprender un poco más sobre los dinosaurios, no era lo que tenía su muestra, pero estuvo re lindo, ija, ja!" Su relato sobre lo que esperaba ver en un museo de historia no se relacionó con las actividades anteriores (como el tratamiento de los folletos), sino con un conocimiento social sobre exhibiciones habituales en los museos a las ciencias naturales. Esta expectativa fue recurrente en otras clases, lo que me llevó a pensar que cierto tipo de museos (los de ciencias naturales) parecen estar más presentes en el conocimiento social de los estudiantes y les resulta más evidente su sentido formativo. Con esto lo que se hace evidente cuando los docentes formulan propuestas amplias de trabajo para recuperar las visitas (por el contrario, cuando orientan a los alumnos de manera más especifica hacia ciertos contenidos a recuperar, estos conocimientos del sentido común quedan más implícitos).

Así como una estudiante dibujó un dinosaurio, la mayoría de los estudiantes dibujó objetos. Lo llamativo de los dibujos y en relación con este eje analítico es que tres alumnos dibujaron armas. 
De Prácticas y discursos

Universidad Nacional del Nordeste

Centro de Estudios Sociales

Año 9, Número 13, 2020, Marzo

ISSN 2250-6942
Pueblos indígenas y prácticas docentes en la escuela secundaria.

El tratamiento de la frontera del sudoeste bonaerense del siglo XIX

Indigenous people and teaching practices in high school. The topic of southwestern of Buenos Aires province [Argentina] frontier in the xixth century

Uno de ellos recrea los tres fusiles (Rémington) de la época de la fundación, los que en la exhibición están dispuestos en forma de triángulo, apoyados en una estructura cuadrada. El dibujo está hecho con lapicera, y el estudiante agregó la leyenda: "Quiero aprobar la materia". Otros dos estudiantes también dibujan armas: uno se asemeja a un fusil visto de costado y está pintado de color marrón y negro en las partes de metal. Otro es un revólver donde la manija está pintada de gris, el mango de color marrón y el metal de color negro. Esta imagen está asociada a una granada pintada de color negro, con una leyenda que dice "Lanza bengalas". Si bien solo el primer dibujo descripto tiene una clara alusión a la "Conquista al Desierto" y así se encuentra exhibido en el museo, las armas en general son sinónimo de violencia. Florencia no problematizó ni contextualizó en el aula estas representaciones, seguramente por una cuestión de tiempo, o porque las armas son objetos presentes en el MAHBB y se ajustaban a la consigna que había planteado.

\section{REFLEXIONES FINALES}

En este artículo presenté algunas conclusiones del trabajo de campo realizado en tres escuelas secundarias del partido de Bahía Blanca en el sudoeste bonaerense, donde focalicé en el tratamiento de diversas problemáticas referidas a la historia local y en particular a los pueblos indígenas en la frontera bonaerense en el siglo XIX. Estos planteos tuvieron como propósito presentar algunas tensiones que se desarrollan en las experiencias áulicas de las clases observadas cuando se pone en juego el mandato unificador del Estado nacional y la perspectiva de una ciudadanía desindigenizada.

En primer lugar, las docentes plantearon en sus clases la idea de una frontera donde el intercambio entre la sociedad blanca y la indígena fue dinámico, y que en la vida cotidiana se generaban intercambios de productos para la subsistencia. Por medio de la utilización de distintos recursos como son los folletos de los museos o un power point, pudieron explicar la idea de intercambio, conflicto y la problemática construcción del Estado nacional en el sudoeste bonaerense. Otros de los temas abordados fue el tratamiento de los llamados indios amigos y sus vinculaciones con el gobierno provincial de Rosas. Dicho tratamiento le permitió, a una docente, articular sus conocimientos basados en lecturas especifi- 
De Prácticas y discursos

Universidad Nacional del Nordeste

Centro de Estudios Sociales

Año 9, Número 13, 2020, Marzo

ISSN 2250-6942

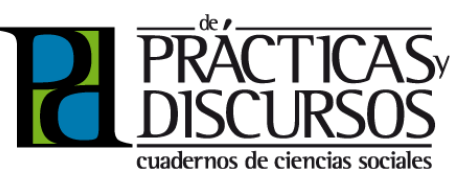

cas, poniendo en relación los temas que aborda en un instituto de formación docente y en sus cursos en la escuela secundaria.

Las docentes mencionaron en sus clases que las zanjas y los fortines fueron parte constitutiva de la edificación de la frontera bonaerense y que, por lo tanto, los pueblos indígenas fueron avasallados por un Estado nacional en construcción. También que la presencia militar fue sostenida y permanente.

En este sentido, en las clases observadas las docentes recuperan con distintas estrategias didácticas aspectos parciales de la historia local que en general cuestionan la visión hegemónica de la imposición de una historia regional sin conflictos. Las prácticas docentes tendieron a destacar la presencia de los pueblos indígenas en la región, la frontera como un espacio de relaciones interétnicas complejas en un contexto histórico donde el Estado nacional estaba en construcción y que no podia dominar el espacio del sur bonaerense a pesar de las sucesivas campañas militares realizadas durante todo el siglo XIX.

Esta reconstrucción de las prácticas docentes permite poner en tensión el tratamiento escolar homogéneo de la historia oficial, la construcción de la nacionalidad y, como consecuencia, la prevalencia de un paradigma que excluye las identidades no indígenas de la Nación argentina.

\section{BIBLIOGRAFÍA}

ACHILLI, E.L. (1985). Enfoque antropológico en la investigación social. Dialogando, 9, 15-22.

(1986). La práctica docente: una interpretación desde los saberes del maestro. Cuadernos de Formación Docente, 1-16.

ALSINA, A. (1977). La nueva línea de fronteras. Memoria especial del Ministerio de guerra y marina, año 1877. Buenos Aires: Eudeba. (Versión original 1877).

BAYÓN, C. Y PUPIO, A. (2003). La construcción del paisaje cultural en el sudoeste bonaerense (1865-1879): una perspectiva arqueológica. En Mandrini, R. y Paz, J. (comps.) Las fronteras hispanocriollas del mundo indigena latinoamericano en los siglos XVIIIXIX (pp. 345-375). Neuquén, Bahía Blanca y Tandil: Centro de Estudios de Historia Regional, Departamento de Humanidades e Instituto de Estudios Históricos Sociales. 
De Prácticas y discursos

Universidad Nacional del Nordeste

Centro de Estudios Sociales

Año 9, Número 13, 2020, Marzo

ISSN 2250-6942
Pueblos indígenas y prácticas docentes en la escuela secundaria.

El tratamiento de la frontera del sudoeste bonaerense del siglo XIX

Indigenous people and teaching practices in high school. The topic of southwestern of Buenos Aires province [Argentina] frontier in the xixth century

BRIONES, C. (2008). Formaciones de alteridad: contextos globales, procesos nacionales y provinciales. En Briones, C. (comp.) Cartografias argentinas: politicas indigenistas y formaciones provinciales de alteridad (pp. 9-36). Buenos Aires: Antropofagia.

DELRIO, W.D. (2015). Caciques, concentraciones y reclutamientos. Campañas de conquista e imposición estatal en el norte de la Patagonia. Revista TEFROS, 13(1), 149-181.

DIRECCIÓN GENERAL DE CULTURA Y EDUCACIÓN DE LA PROVINCIA DE BUENOS AIRES (2008). Diseño curricular para la educación secundaria $3^{\circ}$ año.

GELMAN, J. (2004). La construcción del orden postcolonial. El "sistema de Rosas" en Buenos Aires, entre la cohesión y el consenso. Tiempos de América, 11, 27-44.

LENTON, D. (2010). Presentación del debate: Genocidio y política indigenista. Debates sobre la potencia explicativa de una categoría polémica. Corpus. Archivos virtuales de la alteridad americana, 1(2). Recuperado de http://ppct.caicyt.gov.ar/index.php/corpus

MANDRINI, R. (1992). Pedir con vuelta. ¿Reciprocidad diferida o mecanismo de poder? Antropológicas, Nueva Época, 1, 59-69.

(2008). La Argentina aborigen: de los primeros pobladores a 1910. Buenos Aires: Siglo XXI Editores.

MASES, E.H. (2010). Estado y cuestión indígena: el destino final de los indios sometidos en el sur del territorio (1878-1930). Buenos Aires: Prometeo Libros.

NAGY, M.A. (2012). Tradiciones situadas, usos del pasado y devenir indígena: la Conquista del Desierto y la construcción de hegemonía en la provincia de Buenos Aires (Tesis de Doctorado), Universidad de Buenos Aires, Facultad de Filosofia y Letras, Ciudad autónoma de Buenos Aires, Argentina.

(2013). Los museos de la última frontera bonaerense y sus narrativas acerca de los pueblos indigenas. Revista del Museo de Antropología, 79-90. Recuperado de https://revistas.unc. edu.ar/index.php/antropologia/article/view/5506 
PERRIĖRE, H. (2001). El proceso de ocupación rural en el Valle Inferior del Sauce Chico en la década de 1870. En Actas Octavo Congreso de Historia de los Pueblos de la Provincia de Buenos Aires. Archivo Histórico de la Provincia de Buenos Aires. Recuperado de file://C:/Users/Lark/Desktop/Congresos\%20y\%20jornadas/EL\%20 PROCESO\%20DE\%200CUPACI\%C3\%93N\%2ORURAL\%20EN\%20 EL\%2OVALLE\%2OINFERIOR\%C2\%A0\%20DEL\%20SAUCE\%20 CHICO\%20EN\%20LA\%20DECADA\%20DE\%201870.html

(2003). Un ejemplo de trabajo interdisciplinario en un área de frontera: la ocupación rural del Valle inferior del Río Sauce Chico en el siglo XIX. En Actas II Jornadas Interdisciplinarias del Sudoeste Bonaerense (pp. 77-99). Bahía Blanca: Ediuns.

(2004). El proceso de ocupación rural en el Valle Inferior del Sauce Chico (Partido de Bahía Blanca, década de 1870). En Villar, Daniel y Silvia Ratto (eds.) Comercio, ganado y tierras en la frontera de Bahía Blanca (1850-1870) (pp. 105- 120). Bahía Blanca: Centro de Documentación Patagónica.

(2014). Pueblos originarios, patrimonio y formación del Estado argentino. Del diseño curricular al museo en la escuela. Aportes para la formación docente intercultural. En Menghini, R. A. (ed.) Formación de profesores. La concesión de la utopía: una realidad latinoamericana. (pp. 378-392). Bahía Blanca: El Autor Editorial.

RATTO, S. (2004). La provisión de ganado y artículos de consumo en Bahía Blanca. ¿Los vecinos al servicio del estado o un estado al servicio de los vecinos? En Villar, D. y Ratto, S. (eds.) Comercio, ganado y tierras en la frontera de Bahía Blanca (1850-1870) (pp. 27-62). Bahía Blanca: Centro de Documentación Patagónica.

ROCKWELL, E. (2009). La experiencia etnográfica. Historia y cultura en los procesos educativos. Buenos Aires: Paidós.

VILLAR, D. (2012). Las poblaciones indigenas, desde la invasión española hasta nuestros días.

EN OTERO H. (ED.) Historia de la provincia de Buenos Aires. Tomo I: Población, ambiente y territorio (pp. 249-277). Buenos Aires: Edhasa. 
De Prácticas y discursos

Universidad Nacional del Nordeste

Centro de Estudios Sociales

Año 9, Número 13, 2020, Marzo

ISSN 2250-6942
Pueblos indígenas y prácticas docentes en la escuela secundaria. El tratamiento de la frontera del sudoeste bonaerense del siglo XIX

Indigenous people and teaching practices in high school. The topic of southwestern of Buenos Aires province [Argentina] frontier in the xixth century

VILLAR, D. Y JIMÉNEZ, J.F. (2004). Como buche de ñandú. Negocios en la frontera: pulperos, militares, hacendados e indígenas en Bahía Blanca, hacia mediados del siglo XIX. En Villar, D. y Ratto, S. (eds.) Comercio, ganado y tierras en la frontera de Bahía Blanca (1850-1870) (pp. 7-26). Bahía Blanca: Centro de Documentación Patagónica, Departamento de Humanidades. Universidad Nacional del Sur. 